\title{
Principles of strategic management for the development of the road transportation system
}

\author{
Natalia Gennadevna Gavrilenko \\ Omsk Humanitarian Academy, 4th Chelyuskintsev st., 2A, 644105 Omsk, Russia
}

\begin{abstract}
Strategic development of freight road transport in the Russian Federation requires formation of reliance on fundamental economic theory, the absence of which, as of today, according to a number of well-known economists, is the main cause of emerging difficulties in formation and implementation of strategic documents in Russia. Such documents would include Transport strategy of the Russian Federation for the period up to 2030, and therefore, of special importance is the task of clarifying the key principles for strategic management of the development of the road transport system. The article reviews and substantiates the principles of: "consistency", "digitalization", "openness", "established development trajectory", "variety of development paths", "hierarchy of management", "increasing complexity of motivation", "awareness" and "feedback".
\end{abstract}

\section{Introduction}

Strategic development of the economy presumes corresponding development of both basic industries, such as construction, manufacturing, agriculture and trade, and infrastructure fields, where a special role is played by the road transport industry, which ensures the movement of goods in space. Efficient performance of the above function by road transport, as well as the need to cope with the factors of the negative influence of transport on the environment, require the formation of a new road transport management system. Development (RTS) until the year 2030 is described by the Transport Strategy of the Russian Federation, but as of today this strategy is hard to implement [1]. The reason for the current situation, among other things, is the imperfection of strategic planning system in Russia [2,3,4,5,6,7]. Strategic planning issues in Russia started to be reviewed seriously since 1920 (GOELRO plan); in 1922-1925 N.D. Kondratyev proposed a draft General Plan for the restoration and development of agriculture in Russia, in the 50s and 60s, the balance method for planning of the national economy was developed, and finally, in 2014, the regulatory and legal framework for strategic planning in Russia was supplemented by the Federal Law No. 172-FZ "On Strategic Planning in the Russian Federation", which created a list of requirements for the strategic planning system at the federal and regional levels. However, the existing methodological basis for real strategic planning and strategic management is not based on fundamental economic theory, and, therefore, lacks depth, is eclectic and fragmented - this creates serious difficulties not only in the development, but also in the analysis, comparison and aggregation of strategic plans on all levels of the economy [8]. One of the most crucial steps in tackling with this issue during formation of 
the theory of strategic management for development of RTS is the creation of principles, being important regulatory means.

\section{Materials and methods}

The basis for the study is a review of scientific literature, examination of strategic planning documents of the Russian Federation, historical and logical methods, descriptive methods, axiomatic method and method of analogy.

\section{Results}

The essence of the basic principles of strategic management for development of RTS is shown and reviewed below

1. The principle of consistency in management is important for understanding the complex processes and regularities, as well as the complex structure of freight road transport. RTS is viewed as a combination of elements of three subsystems at macrolevel, mesolevel and microlevel, while half of the freight road transport is carried out by transport companies that transport goods to meet the needs of enterprises. Such transport companies provide the functionality of auxiliary business processes of enterprises in other industries. Commercial transportation is mainly performed by entrepreneurs - individuals, as well as large and small businesses. Such structure significantly complicates the management processes in RTS in general.

"The need to use the systems theory in strategic planning is also conditioned by the very essence of strategic planning, since strategic planning is characterized by a generalized and simultaneously complex ("systemic") perception of the subject of strategic planning and its environment" [9].

The essence of systemic thinking and cognition is the perception of objects and phenomena as a system that can be divided by elements that are interconnected and interact with each other, as well as complex perception of the surrounding reality, formation of laws and patterns of the material and non-material world, the use of the revealed laws and patterns in the new reality of the digital economy, while RTS is viewed as an open multilevel system that carries out the transportation of goods by road transport in the Russian Federation, including subjects and objects of management at the macrolevel, mesolevel and microlevel, with the key goal being to achieve the set development indicators through the innovative renewal of the strategic management process in the context of the digitalization of the economy.

2. The principle of digitalization presumes viewing of RTS through a system of parameters that allow their further use in new information technologies based on computer systems, modeling systems, artificial intelligence, which significantly increases the efficiency of cognition and ensures the implementation of federal projects and programs. In the aspect of digital transformation, RTS must be viewed through the following components: performance indicators (KPIs), environment (enterprises, regions, state), executive mechanisms (functions performed by agents at different levels, such as heads of enterprises, civil servants of various levels), sensor data (obtained information regarding the state of the industry). At the same time, the environment today (especially at the enterprise level) is only partially observable - not all the required characteristics and not at all times are reflected in the available information base (statistical information, reports of the Ministry of Transport), is stochastic (the state of the environment is not determined by the current status and actions performed by the subjects of management), is persistent (shortterm actions of macro- and mesolevel management subjects can have long-term 
consequences), dynamic (the environment may change as the subject chooses the next action), discrete (indicators are discrete in terms of reflecting information (day, month, quarter, year)), multi-subject (multitude of subjects).

3. The principle of system openness is conditioned by the fundamental property of the RTS, with the development being facilitated by external environment, feedback and resource flows. Since RTS is an open system, it exchanges matter, energies and information with the environment, it is characterized by moments of bifurcation and a cyclical nature of development. This principle also reflects the fact that the external factors, adding a restraining or stimulating effect, make the system adapt to itself. One of the key specifics of road transport is that it is not an independent industry. The activity in the industry is determined by the functioning of other industries of material production, being an open system immersed in the state's economy and a network of feedbacks interconnected with it" [10].

4. The principle of "established development trajectory" presumes consideration of the main directions of innovative development in society and the economy associated with a change in technological orders.

The onset of the sixth technological order coincided with the Third Industrial Revolution $[11 ; 12 ; 13 ; 14 ; 15]$. The core of this order is formed by cognitive technologies, that is, artificial intelligence technologies that imitate human thinking processes. Gaining new knowledge, making complex managerial and technical decisions, analyzing large data arrays - these are the key goals when creating cognitive systems. Cognitive technologies are created from the achievements of the previous phases of technology development, primarily on the basis of the fifth technological order, associated mainly with the development of information and computer, financial, controlling and remote technologies. Penetration of a new technological order into economic practices leads to the transformation of existing "traditional" institutions, just like the wheel, steam engine and internal combustion engine, being the innovative technologies of their era, led to new forms of social relations, or, according to J. Schumpeter, performed "creative destruction".

The existing trends in the development of strategic management are reflected in national regulations and projects. Thus, the main project, involving the innovative development of the state administration system, is the national project of digital economy. The national project is developed within the frameworks of implementation of the decree of the President of the Russian Federation Vladimir Putin dated May 7, 2018 No. 204 "On national goals and strategic objectives of development of the Russian Federation for the period up to 2024"

Besides, this principle also takes into account the laws of diffusion of innovations, which are an important condition for general progress. The diffusion of innovations is always dominated by their expansion from more developed innovation systems to less developed ones.

5. The principle of "diversity of development paths" calls for significant attention to external factors, the impact of which significantly increases the grade of diversity of possible development paths. This principle follows the principle of "system openness". Implementation of the principle of "diversity of development paths" complicates the processes of strategic system management, calling for formation of flexible strategies. This principle justifies the need for the formation of processes of correction of strategic plans within the framework of strategic management of development of RTS.

6. The principle of "management hierarchy" assumes the availability of several levels in the road transport system. The goals set for RTS are achieved due to a wave of control actions, starting from the macrolevel and reaching the performers of freight traffic. Management action from the macro-, meso- and microlevels has its own capabilities and specifics, which should be taken into account in the process of strategic management. 
7. Complementing the principle of "hierarchy of management" is the principle of "increasing complexity of motivation". While the actions by the human factor at the microlevel are primarily described by the theory of the "economy man", where in their economic decisions a human acts as a "rational egoist", since the purpose of creating commercial enterprises is to make a profit. The higher in the hierarchy is the subject of management, the more complex is its system of motivation, where in addition to the financial component, the realization of personal "ideas" is becoming more and more important, acting as reasons for changes $[16,17,18,19]$, strife to gain and retain power, etc. The use of artificial intelligence in strategic management is aimed at leveling the aspects of human personality that hinder the development of RTS.

8. Management action is carried out through the implementation of a certain set of functions within the available powers. The selected set of functions should allow the subject of management to direct the development of the system towards reaching the established KPI's. Consequently, creation of strategic documents requires an analysis of the relevance of managerial functions compared to the required conditions for achieving the established indicators. Thus the principle of updating managerial functions acquires special significance. This principle is similar to the principle of functions update, formulated by M.I. Setrov [20], reflecting the tendency of the system to develop as a continuous process of formation of the functions of its elements.

9. Principle of "awareness". "Individuals make choices based on subjectively formed models that differ from one individual to another. The information received by the actors is so incomplete that in most cases these divergent subjective models do not demonstrate a tendency to converge" [21,22]. All decisions of a human resource are based on the information they have. Of greatest importance for the system are decisions of the subject of management and the higher the awareness of the subject, the higher the efficiency of strategic management. Possessing the reliable and timely information allows one to quickly react to changes and make constructive management decisions. Formation of a unified information base allows to significantly increase the awareness of the subjects.

10. Complementing the principle of awareness is the principle of "feedback" in the system. This principle allows harmonizing the interests of all levels of management to make constructive decisions aimed at innovative transformations. Timely procurement of information is a systemic factor, source and root cause for modernization. The awareness of the management subject can be complete only under condition of timely receipt of fresh information on the state of the management object, its response to managerial action, as well as on the obstacles that arise before the achievement of the established KPIs. If the feedback does not allow the control system to be informed about the state of the controlled system (due to the congestion of the channels, delay and information distortions), the efficiency of innovation management is reduced to zero.

\section{Conclusions}

The principles described above are formulated in accordance with the systemic approach, as ones most relevant to the issues of strategic management of the development of RTS. However, while the principles of "consistency" and "digitalization" can be attributed to the systemic approach in general, the principles of "hierarchy of management", "increasing complexity of motivation", "awareness", "feedback", "actualization of management functions" are characteristic of the cybernetic aspect of the systemic approach (this aspect refers to "power" management, artificially lining up the system for defined purposes), and the principles of "established development trajectory", "openness", "diversity of development paths" are characteristic of the synergistic aspect (this aspect corresponds to a "soft" management impact, it is believed that the restructuring process generally occurs 
under the influence of external factors and development trends). It must be noted that at each management level, certain principles prevail, depending on the dominant aspect (Fig. 1)

The use of the reviewed principles allows designating the benchmarks in the process of forming a strategic management system for the development of RTS, taking into account the complexity of the RTS management structure, including the fact that there is no possibility of direct influence on the microlevel of management (represented mainly by the commercial sector) from the meso- and macrolevels.

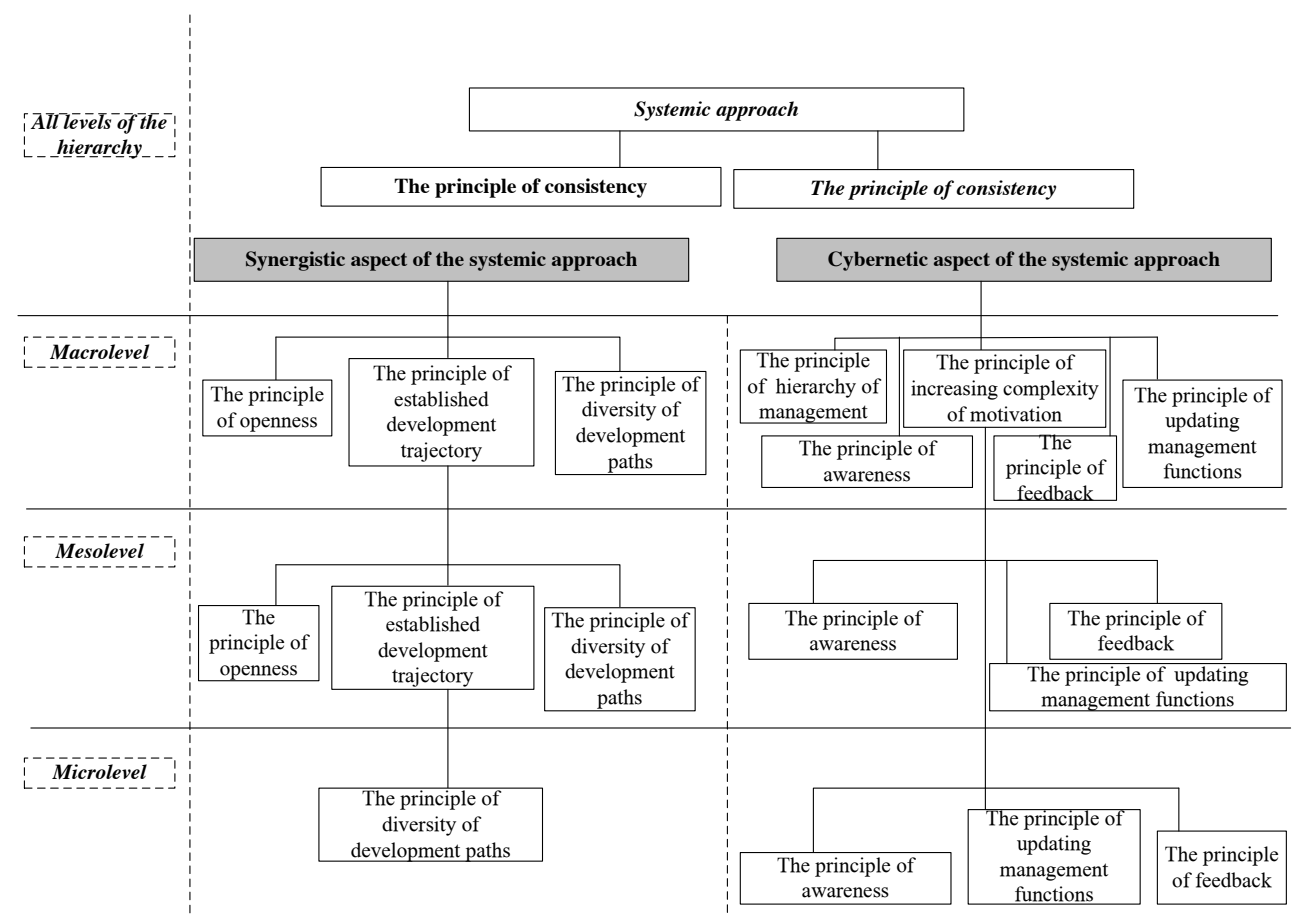

Fig. 1. Principles of strategic management of RTS at different levels of the hierarchy

\section{References}

1. S.A. Borodulina, N.G. Gavrilenko, Human Science: Humanitarian studies, 1, 217 (2020)

2. N.V. Zubarevich, Economic Issues, 1, 135 (2019)

3. V.A. Mau, Economic Issues, 3, 5 (2019)

4. E.G. Yasin, Economic Issues, 6, 5 (2018)

5. Viktor Sebestyén, Endre Domokos, János Abonyi, Journal of Environmental Management, 263 (2020)

6. A. Jessica, Social Networks, 29(4), 469 (2017)

7. Henrik Lund, Frede Hvelplund, Energy, 43(1), 192 (2012)

8. G.B. Kleiner, Economic Issues, 11, 127 (2019)

9. G.B. Kleiner, Development of the theory of economic systems and its application in corporate and strategic management, https://kleiner.ru/ 
10. L.B. Mirotin, V.A. Gudkov, V.V. Zyryanov, Managing cargo flows in transport and logistics systems, 29 (2010)

11. V.M. Averbukh, Bulletin of StavGU, 71, 159 (2010)

12. S. Yu. Glazyev, D. S. L'vov, G. G. Fetisov, Evolution of technical and economic systems: opportunities and boundaries of centralized regulation, 207 (1992)

13. L. K. Gurieva, Innovations, 10, 70 (2004)

14. L. I. Lopatnikov, Economic and mathematical dictionary: Dictionary of modern economic science, 520 (2003)

15. G. G. Malinetskiy, Modernization - a course for the 6th technological order, 41, 16 (2010)

16. R. Lieberman, American Political Science Review, 96(4), 697 (2002)

17. C. Parsons, International Organization, 56(1), 47 (2002)

18. S.V. Patrushev, Political Science, 3, 5 (2009)

19. O. Yu. Malinova, Polis, 3, 90 (2010)

20. M.I. Setrov, Fundamentals of the functional theory of organization, 164 (2010)

21. D. North, Institutions, institutional change and economic performance (1990)

22. V.L. Tambovtsev, Issues of Economics, 5, 26 (2019) 